British Journal of Industrial Medicine 1988;45:577-580

\title{
Editorial
}

\section{Work and pregnancy}

In this issue is published the last of six reports describing the main findings in a large survey in Montreal designed to assess the effect of occupational factors on the outcome of pregnancy in employed women. ${ }^{1-6}$ This seems an appropriate occasion to review current knowledge on the subject including that contributed by the Montreal survey. In the latter some 56000 women in 11 hospitals covering $90 \%$ of Montreal births were interviewed soon after delivery and questioned about personal, social, and occupational factors in their recent and all previous pregnancies-some 104000 in all.' Increasing numbers of women are employed and working when they become pregnant; they need to know whether they can continue without risk to the fetus. Mechanisms of fetal damage can be investigated in small laboratory mammals, but because they differ from man in reproductive physiology, susceptibility to chemicals and other potentially hazardous factors, and also in size (making it difficult to compare "dose"), findings cannot readily be extrapolated to man. Direct human observations are therefore needed. Because there have been few promising hypotheses to test, attempts to detect hazards have generally entailed descriptive epidemiological studies which when large numbers of factors are examined make it difficult to distinguish chance from causality. Interpretation must thus depend on the strength and plausibility of observed associations and consistency between studies. The adverse outcomes of concern are spontaneous abortion (here referred to as abortion), stillbirth, congenital defect, and prematurity ( $<37$ weeks gestation or $\leqslant 2500 \mathrm{~g}$ in weight).

Whether or not employment per se endangers the fetus cannot easily be answered because of the many confounding factors associated with both the decision to work and the risk of an adverse outcome. Both high and low rates of prematurity have been found in employed women compared with those who were not employed ${ }^{7-10}$ Observations on pregnancy outcome in occupational groups classified in a standard manner give useful leads when consistent between different studies. Rates of spontaneous abortion (in hospital or polyclinic) were calculated for eight main maternal occupational groups in Finland by linking hospital discharge data and occupation recorded prenatally. ${ }^{.1}$ After standardisation for age, an increased risk of abortion was found for industrial and construction work and for agriculture, forestry, and fishing, and a diminished risk in managerial and clerical work. In a more detailed occupational analysis metal and electrical factory work carried an increased risk ${ }^{12}$ and two other studies have suggested an increased risk from work with metals. ${ }^{1314}$ In Montreal, after allowing by logistic regression for seven confounding variables, numbers of abortions observed were compared with numbers expected in six main employment sectors. The risk was found to be increased in sales and services and decreased in managerial and clerical sectors. Of 60 occupational groups into which all women at work were classified, an increased risk was found in nursing aides, food and beverage service, certain sales occupations, and work in factories that made metal, electrical, and certain other goods. ${ }^{4}$

Preterm birth ( $<37$ weeks gestation), after allowance for age, parity, outcome of previous pregnancies, and complications of pregnancy, was found in France to be above average in shop employees, medicosocial workers, unskilled workers, and cleaning staff whereas teachers, office staff, and skilled workers had a less than average risk. ${ }^{15}$ In Montreal after allowing for eight confounding variables the risk of preterm birth was somewhat raised in the services sector and of low birth weight in manufacturing. From 60 occupational groups an excess of preterm birth was seen in food and beverage service and in psychiatric nursing and of low birth weight in food and beverage service, chambermaids and cleaners, and the manufacture of metal, electrical, and certain other products.

Congenital defects have been studied in Finland using a register maintained since 1963 with a smaller "research register" of selected marker defects and controls. ${ }^{16}$ Occupation is classified from the prenatal record and cases and controls are routinely investigated for exposures during occupational and leisure time activities. Industrial and construction work was found to be associated with central nervous system and musculoskeletal defects and transport and communication with oral clefts. ${ }^{17}$ In a more recent analysis agricultural and horticultural work was also 
associated with oral clefts (K Kurppa et al, personal communication). In the United States an occupational study of congenital defects registered in a five county area round Atlanta, Georgia, found an association between oral clefts and both nursing and printing work. ${ }^{18}$ In Montreal no link was found with oral clefts, central nervous, or musculoskeletal defects but a group of anomalies excluding chromosomal and musculoskeletal defect and hernias was increased in agriculture and horticulture. ${ }^{6}$ This lack of consistent findings on occupation and congenital defect is not surprising in that causal associations would probably be with specific defects, the frequencies of which are generally too low for detection even in a large survey.

A few occupations have received special attention. Work in operating rooms was found in several questionnaire surveys to carry an increased risk of abortion but two recent studies with verification in hospital records gave negative results. ${ }^{190}$ In a survey of anaesthetists no risk of abortion but an increase in stillbirth was found. ${ }^{21}$ In Montreal there was no excess of abortions at less than 16 weeks gestation but a significant excess at a later stage. It seems possible that work in operating rooms may carry a risk of late rather than early fetal death. ${ }^{21}$ In three series of laboratory workers an excess of abortions was reported ${ }^{1422} 23$ but in two more detailed studies, with abortions verified in hospital records, no association was observed. ${ }^{2024}$ An increase in serious congenital defects, especially of gastrointestinal atresia, was reported in Swedish laboratory workers. ${ }^{25}$ This was confirmed in a casecontrol study of 200 cases of this defect, seven cases were in laboratory workers against 2.5 expected. ${ }^{26}$ In Montreal, no excess of either abortion or congenital defect was seen in laboratory workers. In a perinatal mortality survey in Leicestershire leatherworkers were found to have a significant excess of macerated stillbirths and of a rare congenital defect trisomy $18 .^{27}$ The Montreal survey was of insufficient size to test the latter hypothesis but, despite small numbers, there was a significant excess of stillbirths without defect, adding credence to the hypothesis and throwing suspicion on solvents used in glues. ${ }^{28}$ Work in plastics factories in Finland showed a significant increase in abortion among women engaged in the manufacture of polyurethane ${ }^{29}$; in Montreal there were too few polyurethane workers to test this hypothesis but an association with polystyrene manufacture was found. ${ }^{30}$ There were no reinforced plastics workers in Montreal whereas, in Finland, the exposures to styrene were mainly in that type of process.

Visual display units (VDUs) are increasingly used in many occupations, especially in the clerical sector. In 1978-80 some clusters of abnormal pregnancy outcomes were reported and given much publicity. Very low frequency electromagnetic fields and unsatisfac- tory ergonomic features of the work were proposed as possible causes but without known biological mechanisms. In the Montreal survey it was possible to study VDU use in relation to the four adverse pregnancy outcomes. ${ }^{5}$ All analyses were negative except that a greater use of VDUs was reported by women who had just had an abortion compared with women who had recently had a normal delivery. In past pregnancies there was no excess. This single positive finding in recently completed pregnancies was thought to have arisen from (1) better recall of VDU use by women who had just aborted compared with women who were questioned six months later and (2) biased response due to overreporting of VDU use by women who had aborted and underreporting by those who had normal babies. Certainly, regression analyses based on the 60 occupational groups showed no higher risk in groups with frequent VDU use than in those with little or none. In Sweden, too, no increased risk of abortion or congenital defects was reported ${ }^{31}$ nor in Finland of congenital defects. ${ }^{32}$

Physical stress has long been thought to cause abortion and confirmation of this was found in the Montreal survey. Heavy lifting in the pharmaceutical industry in Finland gave a substantially increased risk of abortion. ${ }^{33}$ Rotating shift work in laboratories in Sweden was also associated with abortion. ${ }^{24}$ In Montreal frequent heavy lifting was accompanied by an increased risk of abortion in all six employment sectors - other physical effort, standing, long hours of work, and changing shift work, less consistently. Because, in the Montreal survey, both interviewer and subject knew the outcome of the pregnancy and responses recorded might have been biased, a further "grouped" or "ecological" analysis was undertaken in the 60 occupational groups, as was done for VDUs. This time the analyses showed that the increased risks of abortion in work entailing physical stress were not attributable to recall bias.

The prematurity rate in Washington State did not appear to be affected by physical activity at work $^{34}$; in France, on the other hand, a complex index of physical fatigue was found by Mamelle and colleagues to correlate with preterm birth. ${ }^{15} \mathrm{~A}$ similar fatigue index in Montreal was also associated with preterm birth, although less strongly than in the French data. Lifting heavy weights, a long working week, and changing shift work were less consistently associated with both preterm and low birth weight. ${ }^{3}$ Further analyses of birth weight allowing for gestational age suggested that the main effect of long working hours and fatigue, as measured by the index, was to shorten gestation whereas lifting heavy weights and changing shift work appeared to reduce the rate of fetal growth as well.

Exposures to chemicals have aroused more concern than physical stress. In Finland occupations recorded 
in the 1975 census for women and their husbands were linked to hospital birth and abortion discharge data for 1973-6, giving information on 294309 pregnancies. ${ }^{23}$ These were allocated to seven groups of occupations presumed to entail exposure to solvents, automobile exhaust fumes, polycyclic aromatic hydrocarbons, other chemicals, metals, textile dust, and animal micro-organisms respectively. No excess risk of abortion was detected for maternal (or paternal) occupation in any of the seven groups. In Denmark several occupations with presumed exposures to chemicals were investigated in a somewhat similar manner but with additional information on exposure from questionnaires. ${ }^{35}$ Dental assistants (exposed to nitrous oxide and inorganic mercury) and gardeners (exposures to pesticides) had no increased risk of abortion but painters and women in certain factories which used solvents were at increased risk. ${ }^{36}$ Exposure in the pharmaceutical industry to the solvent methylene chloride was also associated with an increased risk of abortion. ${ }^{33}$ In the Finnish casecontrol studies of congenital defect exposure to solvents was reported to be associated with central nervous system defects but this was not confirmed in a later period. ${ }^{16}$

In Montreal two methods were used to investigate chemical exposures. Firstly, specific occupations were identified where it was estimated from worksite visits that exposures to chemicals reached at least $30 \%$ of the TLV. Four types of exposure were analysed: solvents, anaesthetic gases, pesticides, and other chemicals. Only exposure to solvents in the manufacturing sector was significantly associated with abortion (a $20 \%$ increase in risk) and with stillbirth (a two to threefold increase). Secondly, a case-referent study of 300 cases of congenital defect and 300 matched referents was undertaken. ${ }^{2}$ Workplaces were visited by hygienists without knowledge of the identity of cases and referents. All exposures to chemicals classified in nine categories were recorded by estimated intensity and one category-the aromatic solvents (especially toluene)-showed an association with congenital defects mainly but not exclusively of the renal urinary tract.

The administration of mutagenic antineoplastic drugs by pregnant nurses has been a source of anxiety. In Finland an excess of abortions was reported in nurses exposed in this way ${ }^{37}$ and a small but significant excess of registered malformations in their children. ${ }^{20}$ In Montreal an excess of defects but not of abortions was observed when antineoplastic drugs were handled in early pregnancy. The eight defects were miscellaneous in type and included three cases of club foot and two of hernia. In the Finnish study the defects apparently also varied and included limb defects. Agricultural chemicals may well be fetotoxic or teratogenic: there was evidence during the peak period of agricultural chemical use in the United States of an excess of clefts of the lip or palate, or both, related to exposure in the first trimester. ${ }^{38}$ In New Zealand monthly spraying of 2-4-5-T from 1960 to 1977 was linked to routinely recorded stillbirths and congenital malformations; the only statistically significant association was with talipes. ${ }^{39}$ In Montreal, where few pregnancies were thought to have had exposure to pesticides, their outcome was normal.

It is evident from this brief review that many conflicting findings have been reported on the outcome of pregnancy in working women. There are several reasons for this: $(a)$ many studies are small in terms of the number of women exposed and the number of abnormal outcomes; $(b)$ the number of potential associations investigated is large and, as a result, some may appear "statistically significant," (c) a large number of non-occupational factors, many still unknown, affect the outcome of pregnancy, and (d) answers to questions given by women after emotionally traumatic events, such as fetal death or serious defect, may be influenced by this experience. Sources of potential bias, inherent in retrospective inquiries, cannot yet be readily eliminated even in prospective cohort studies, due to the fact that pregnancy and therefore early abortion is largely self diagnosed. The problem may possibly be overcome when it is feasible to determine conception by reliable objective tests in large well designed epidemiological surveys.

On current evidence it thus seems reasonable to conclude that:

(1) For most pregnant women, especially those in clerical and administrative occupations, there is good evidence that employment carries no risk.

(2) Heavy physical effort and unsatisfactory working conditions, especially in manufacturing, services, and sales sectors, may lead to spontaneous abortion and preterm birth; it is prudent that these should be avoided.

(3) The indications that organic solvents may be fetoxic and perhaps teratogenic warrant further study. A D MCDONALD

4 Temple West Mews,

West Square,

London SE11 4SN.

\section{References}

1 McDonald AD, McDonald JC, Armstrong B, et al. Occupation and pregnancy outcome. $\mathrm{Br} J$ Ind Med 1987;44:521-6.

2 McDonald JC, Lavoie J, Cote R, McDonald AD. Chemical exposures at work in early pregnancy and congenital defect: a case-referent study. Br J Ind Med 1987;44:527-33.

3 McDonald AD, McDonald JC, Armstrong B, Cherry NM, Nolin AD, Robert D. Prematurity and work in pregnancy. Br J Ind Med 1988;45:56-62. 
of pregnancy among women in anaesthetic practice. Lancet 1977;i:34-6.

and work in pregnancy. $\mathrm{Br} J$ Ind Med 1988;45:148-57.

5 McDonald AD, McDonald JC, Armstrong B, Cherry NM, Nolin $\mathrm{AD}$, Robert $\mathrm{D}$. Work with visual display units in pregnancy. $\mathrm{Br}$ J Ind Med 1988;45:509-15.

6 McDonald AD, McDonald JC, Armstrong B, et al. Congenital defects and work in pregnancy. Br J Ind Med 1988;45:581-8.

7 Stewart A. A note on the obstetric effects of work during pregnancy. Br J Prev Soc Med 1955;9:159-61.

8 Naeye RL, Peters EC. Working during pregnancy: effects on the fetus. Pediatrics 1982;69:724-7.

9 Saurel-Cubizolles MJ, Kaminiski M. Pregnant women's working conditions and their changes during pregnancy: a national study in France. Br J Ind Med 1987;44:236-43.

10 Murphy JF, Dauncey M, Newcombe R, Garcia J, Elbourne D. Employment in pregnancy: prevalence, maternal characteristics, perinatal outcome. Lancet 1984;i:1163-6.

11 Hemminki K, Niemi M-L, Vainio H, Hemminki E. Spontaneous abortions by occupation and social class in Finland. Int $J$ Epidemiol 1980;9:149-53.

12 Hemminki K, Niemi M-L, Koskinen K, Vainio H. Spontaneous abortions among women employed in the metal industry in Finland. Int Arch Occup Environ Health 1980;47:53-60.

13 Nordstrom S, Beckman L, Nordenson I. Occupational and environmental risks in and around a smelter in northern Sweden. V Spontaneous abortion among female employees and decreased birth weight in their offspring. Hereditas 1979;90:291-6.

14 Vaughan TL, Daling JR, Starzyk PM. Fetal death and maternal occupation. An analysis of birth records in the state of Washington. J Occup Med 1984;26:676-8.

15 Mamelle N, Laumon B, Lazar P. Prematurity and occupational activity during pregnancy. Am J Epidemiol 1984;119:309-22.

16 Kurppa K, Holmberg PC, Hernberg S, Rantala K, Riala R, Nurminen $T$. Screening for occupational exposures and congenital malformations. Scand J Work Environ Health 1983;9:89-93.

17 Hemminki K, Mutanen P, Luoma K, Saloniemi I. Congenital malformation by the parental occupation in Finland. Int Arch Occup Environ Health 1980;46:93-8.

18 Erickson JD, Cochran WM, Anderson CE. Parental occupation and birth defects. A preliminary report. Contributions to Epidemiology and Biostatistics 1979;1:107-17.

19 Axelsson G, Rylander R. Exposure to anaesthetic gases and spontaneous abortion: response bias in a questionnaire survey. Int J Epidemiol 1982;11:250-6.

20 Hemminki K, Kyrronen P, Lindbohm M-L. Spontaneous abortions and malformations in the offspring of nurses exposed to anaesthetic gases, cytostatic drugs, and other potential hazards in hospitals, based on registered information of outcome. $\mathrm{Br} \mathrm{J}$ Ind Med 1985;39:141-7.

21 Pharoah POD, Alberman E, Doyle P, Chamberlain G. Outcome
22 Strandberg M, Sandback K, Axelson O, Sundell L. Spontaneous abortions among women in a hospital laboratory. Lancet 1978;i:384-5.

23 Lindbohm M-L, Hemminki K, Kyrronen P. Parental occupational exposure and spontaneous abortions in Finland. Am J Epidemiol 1984;120:370-8.

24 Axelsson G, Lutz C, Rylander R. Exposure to solvents and outcome of pregnancy in university laboratory employees. $\mathrm{Br} \mathrm{J}$

25 Meirik O, Kallen B, Gauffin V, Ericson A. Major malformations in infants born of women who worked in laboratories while pregnant. Lancet 1979;ii:91.

26 Ericson A, Kallen B, Meirik O, Westerholm P. Gastro-intestinal atresia and maternal occupation during pregnancy. $J$ Occup Med 1982;24:515-8.

27 Clarke M, Mason ES. Leatherwork: a possible hazard to reproduction. Br J Ind Med 1985;290:1235-7.

28 McDonald AD, McDonald JC. Outcome of pregnancy in leatherworkers. Br J Ind Med 1986;292:979-81.

29 Lindbohm M-L, Hemminki K, Kyrronen P. Spontaneous abortions among women employed in the plastics industry. Am J Ind Med 1985;8:579-86.

30 McDonald AD, Lavoie J, Cote R, McDonald JC. Spontaneous abortion in women employed in plastics manufacture. Am J Ind Med (in press).

31 Westerholm P, Ericson A. Pregnancy outcome and VDU work in a cohort of insurance clerks. In: Knave B, Wideback PG, eds. Work with display units. Stockholm: Elsevier, 1986:104-10.

32 Kurppa K, Holmberg PC, Rantala K, Nurminen T, Saxen L. Birth defects and exposure to video display terminals during pregnancy. Scand J Work Environ Health 1985;11:353-6.

33 Taskinen H, Lindbohm M-L, Hemminki K. Spontaneous abortions among women working in the pharmaceutical industry. $\mathrm{Br}$ J Ind Med 1986;43:199-205.

34 Meyer BA, Daling JR. Activity level of mothers' usual occupation and low birth weight. J Occup Med 1985;27:841-7.

35 Heidam LZ. Spontaneous abortions among laboratory workers: a follow-up study. J Epidemiol Community Health 1984;38:36-41.

36 Heidam LZ. Spontaneous abortions among dental assistants, factory workers, painters, and gardening workers: a follow-up study. J Epidemiol Community Health 1984;38:149-55.

37 Selevan SG, Lindbohm M-L, Hornung RW, Hemminki K. A study of occupational exposure to antineoplastic drugs and fetal loss in nurses. $N$ Engl J Med 1985;313:1173-85.

38 Gordon JE, Shy CM. Agricultural chemical use and congenital cleft lip and/or palate. Arch Environ Health 1981;36:213-21.

39 Hanify JA, Metcalf $P$, Nobbs CL, Worsley KJ. Aerial spraying of 2-4-5-T and human birth malformations: an epidemiological investigation. Science 1981;212:349-51. Ind Med 1984;41:305-12. 